\title{
The changes in airline network configurations (especially temporal configurations) in Europe
}

\author{
K. Nedvědová \\ Transport Department, Brno City Municipality, Czech Republic \\ Department of Geography, Masaryk University, Czech Republic
}

\begin{abstract}
The topic of this article is concerned with the changes of airline network configurations (mainly temporal concentration) in Europe. Air transport in Europe reached significant milestones in 1997, when the air transport became fully liberalized (country from EU 10 in 2004 after their entry to EU). Airline liberalization influenced the configuration of airline networks into hub-andspoke system that is typical by temporal and spatial concentration. The temporal concentration is connected with the adoption or intensification of wave-system structures that considerably influenced overall traffic growth. The wave system structure is the complex of incoming and outgoing flights that are organized such that all incoming flight has connection to all outgoing flights. It is known that airports with wave system perform better due to the number of direct connections via hub. Therefore changes will be observed in transport strategies between years 2005 and 2013, specifically 2005, 2009 and 2013 in the "typical day" - Tuesday in June. The selected area for research is 19 countries in Central and Eastern Europe. The main airports and also the primary airlines (mainly classical airlines) are selected for the counting of wave-system structures in these countries. The main interest should be in the results of differences between airports as a result of their urban hierarchy and also their location in Europe (political and historical differences), which are or are not affected by the liberalization of air transport. It is expected that airports in countries such as Germany or Austria should have more efficient temporal concentration compared with countries such as Czech Republic or Hungary. This is due to the size of city where the airport is located and the liberalization of air transport in Europe.
\end{abstract}

Keywords: airline liberalization, airline networks, wave-system structure, temporal distribution. 


\section{Introduction}

Radical changes have taken place in European air transport since the 1990s when air transport liberalization was introduced and then successfully completed in 1997. Countries concerned with these changes included the EU countries, and Iceland, Norway and Switzerland and later on the new EU members joining after 1997. Important events that occurred as result of liberalization included the arrival of low-cost airlines, the forming of airline alliances, and mainly changes in airline network configurations.

We can see both spatial and temporal configurations of flights in airline networks. These two characteristics together (spatio-temporal configuration) represent the basic features of a 'hub-and-spoke' network as this type of airline network has the maximum level of coordination of both time and space components. On the other hand the 'point-to-point' network popular predominantly among low-cost operators features no significant concentration of time or space configuration of its airline networks and if it does, it is mostly randomly formed.

This article deals with the temporal configuration of European airline networks. "The temporal configuration can be defined as the number and quality of indirect connections offered by an airline or alliance by adopting a wavesystem structure in the airline flight schedule" (Bootsma in Cento [5]).

The number and quality of indirect connections can be increased by concentrating the regular flights into certain time slots, i.e. adopting the "wave system' for regular flights $[1,2]$.

\section{Temporal configurations and applied methodology}

The temporal configuration concept is based on observations indicating that airlines tend to synchronize their operations (daily waves of flights through hub airports). The purpose of such a structure is to optimize the number and quality of offered connections. It has been proven that airports with the wave system structure offer more indirect connections than those without it, considering a certain number of direct flights $[1,3]$.

As a large number of airlines, mainly the traditional ones, endeavour to incorporate their flights in a wave system in which arrivals and departures are concentrated into specific time slots so that the flights interconnect, the existence of the wave system will be analysed from the temporal configuration point of view. An assumption can be made that the existence of a wave system is more important for traditional airlines that do not run their own business as point-topoint and have a large indirect connectivity compared to low-cost airlines that are typical for their point-to-point way of operating.

The wave system is formed by inter-connection waves consisting of a sum of arrivals and departures organized in such a way that all departures are connected to all arrivals. The temporal wave system maximizes the number of interconnections in a limited time compared to the number of direct flights. The temporal wave system is typical for large airports as it would be inefficient for 
small ones that serve predominantly direct flights, the main purpose of which is not to connect to other flights - as with low-cost operators, for example. Yet Skyeurope, a former low-cost operator introduced the Skylink service between Košice and Bratislava in Slovakia. Skyeurope, as explained by Malighetti [8], did not coordinate their flights, but rather guaranteed a connection if a flight from Košice was delayed by up to 30 minutes.

As DHV CR \& InterVITAS [9] write, while a new charter flight or a low-cost operator's flight extend the portfolio by one traveling option, a new flight to one of the European hubs creates tens if not hundreds of new possibilities for passengers. The particular example of the city of Brno airport was used. For that reason a line to the network of hub airports is considered a high priority to attract attention and possible involvement of the public sector in further development of services not only at Brno airport but other airports as well.

Data from http://www.flightstats.com /go/Home/home.do has been used for the temporal configuration of airline networks and thus for the analysis of wave system. Data from the periods of 2005, 2009, 2012 and 2013 and a particular workday (Tuesday) in June has been selected.

The interconnection wave configuration itself has been designed following a methodology applied by Burghouwt $[2,4]$. In order to simplify the wave system structure, the minimum changeover time has been set typically at between 30 and 40 minutes with respect to the data available from particular airports. The same will be used for structuring the interconnection waves in this case. 90 minutes has been set as the maximum changeover time. Flights that land between $\mathrm{t}=\mathrm{C}-45$ and $\mathrm{t}=\mathrm{C}-\mathrm{x}$, and take off between $\mathrm{t}=\mathrm{C}+\mathrm{x}$ and $\mathrm{t}=\mathrm{C}+45$ are included in the wave being compiled. $\mathrm{C}$ in the formulas represents the wave centre that shifts every 6 minutes.

The wave system structure consists of a certain number of waves, their times and of the individual wave's makeup. An ideal hub interconnection wave is illustrated in Fig. 1. According to Burghouwt and de Wit [2], a wave is a sum of arrivals and departures drawn up in such a way that all departures connect to all arrivals. Three components determining the makeup of each wave are important: a) minimum changeover time for continental and intercontinental flights, b) maximum changeover time and c) maximum number of flights that can be realized in the given period [2-6].

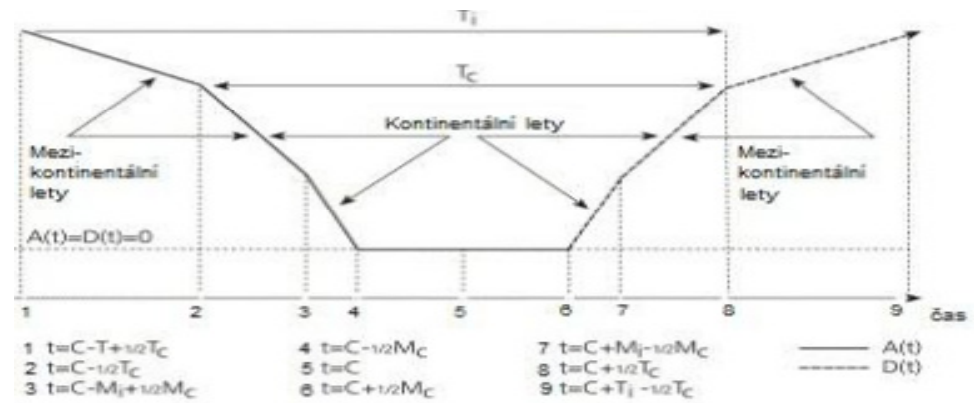

Figure 1: Theoretical connection wave [2]. 
An area of interest has been delimited within Europe: Central and Eastern Europe, which included the following 17 countries - Belarus, Bulgaria, the Czech Republic, Estonia, Croatia, Lithuania, Latvia, Hungary, Moldova, Germany, Poland, Austria, Rumania, Slovakia, Slovenia, Switzerland and Ukraine.

Studying the airline network development in Central and Eastern Europe is interesting due to a different level of CEE economies as well as from a historical point of view. While air traffic liberalization in Germany, Austria and Switzerland was finalized in 1997, this only happened after their joining the EU in 2004 and in 2007 in the other countries (with the exception of Belarus, Croatia, Moldova and Ukraine where the air market was not fully liberalized). These countries had different conditions for their air transport market development compared to Germany, which has one of the most advanced air transport markets in Europe. Therefore one of the tasks of the analysis will be to find out whether airports in Germany, Austria and Switzerland have more coordinated systems of temporal configuration and more spatially concentrated flights compared to other airports. In addition to this, attention will be paid to changes that occurred after air transport liberalization where the largest changes can be expected in countries, which adopted the liberalization policy after 1997. In the overall view, air transport development in Europe is interesting due to the large number of countries and thus a large number of unique markets on this continent as opposed to the deregulated market of the United States of America. The following 18 airports have been selected for further study, being the largest in each country (typically in the capital) and accommodating a strong national airline:

Central Europe (Bratislava, Budapest, Frankfurt, Ljubljana, Munich, Prague, Warsaw, Vienna, Zagreb and Zurich).

Eastern Europe (Bucharest, Chisinau, Kiev, Minsk, Riga, Sofia, Tallinn and Vilnius).

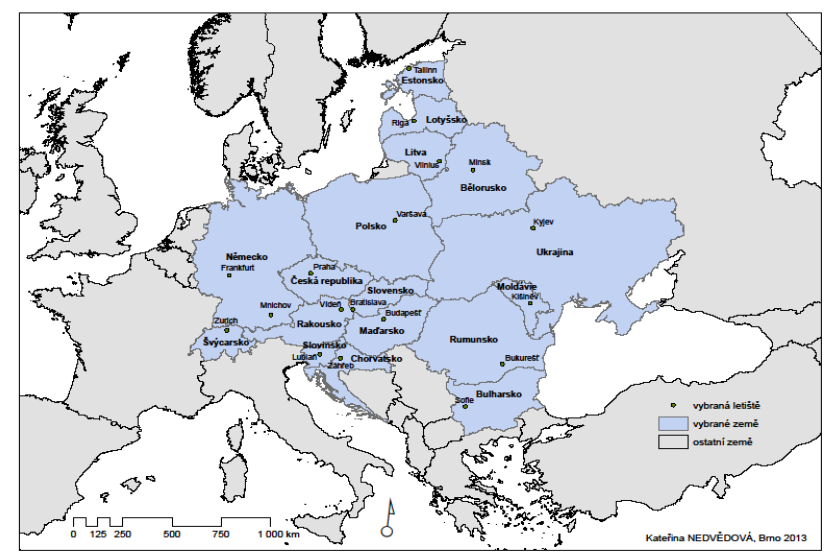

Figure 2: The selected airport in Central and Eastern Europe. 


\section{Wave system}

The wave system is usually analysed for the most important (typically national) airline at the airport, which has also been done for this article. Yet another system analysis could be made for the whole alliance where a particular airline is a member - see Dennis [10] or Murphy [11]. In such a case, it would be interesting to monitor whether the number of waves (or the number of flights within a wave) grows or whether the situation copies that in London-Heathrow, which does not apply the wave system, operating so many flights that a connection to another flight in the required direction is more than likely anyway. This airport situation has been named a 'continuous hub' by Burghouwt [4].

Table 1 presents information associated with the wave system from the selected Central and Eastern European airports. Data on the number of waves in 2005, 2009, 2012 and 2013, and on the quality of the local wave system can be found in it.

The wave quality system has been set in 3 or 4 categories for the purpose of this article: absent, poor, good and very good. Airports with wave system quality classified as absent have no waves at all. The poor category covers airports with up to 8 arrivals/departures in one wave while the good category features between 8 and 16 of them. The last very good category represents more than 16 arrivals/departures in one wave.

Table 1 further divides countries according to their date of joining the EU where the first group features member states before 2004, the second group shows countries that became members in 2004 while the third and fourth groups represent countries that only became EU members after the first year of this analysis and evaluation, i.e. after 2005. The last group covers non-EU countries (Belarus, Moldova and Ukraine).

It can be seen that countries with EU membership before 2004 have stable numbers of waves throughout the monitoring period; similarly the quality of the wave system is good or very good. Airports in countries that joined the EU after 2004 are typical for also having their wave systems even though their quality is not as high as in Munich or Vienna, for example. Airports in Prague and Warsaw are exceptions having good levels of the wave system quality, which may be determined by the locations and sizes of these cities. On the contrary, Bratislava, Budapest and Vilnius do not have their national airlines and therefore no wave system is present there. It is also noticeable that the majority of airports that have a functional wave system are members of an airline alliance, which - together with the existence of the wave system - is a sign of air market liberalization.

It is obvious that airports in non-EU countries that do not have fully liberalized air transport space generally do not apply any wave system to their flights (with some exceptions).

Frankfurt and Munich are among the airports with the highest numbers of waves and highest quality systems. Murphy [11] among others dealt with the coordination of arrivals and departures at Frankfurt and discovered that the temporal waves exist there not only within Lufthansa but also within the whole Star Alliance. This results in successful incorporation of the whole alliance in the 
Table 1: Number and quality of wave-system structure on selected airport in Europe.

\begin{tabular}{|c|c|c|c|c|c|c|c|c|c|}
\hline \multirow[b]{2}{*}{ Airport } & \multirow[b]{2}{*}{ Airline } & \multicolumn{4}{|c|}{ Quality of wave-system structure } & \multicolumn{4}{|c|}{ Number of waves } \\
\hline & & 2005 & 2009 & 2012 & 2013 & 2005 & 2009 & 2012 & 2013 \\
\hline Frankfurt & Lufthansa(S) & $\begin{array}{l}\text { very } \\
\text { good }\end{array}$ & good & $\begin{array}{l}\text { very } \\
\text { good }\end{array}$ & $\begin{array}{l}\text { very } \\
\text { good }\end{array}$ & 4 & 4 & 4 & 4 \\
\hline Munich & Lufthansa (S) & good & good & $\begin{array}{l}\text { very } \\
\text { good }\end{array}$ & $\begin{array}{l}\text { very } \\
\text { good }\end{array}$ & 5 & 5 & 5 & 5 \\
\hline Vienna & $\begin{array}{l}\text { Austrian } \\
\text { Airlines (S) }\end{array}$ & good & poor & good & $\begin{array}{l}\text { very } \\
\text { good }\end{array}$ & 5 & 5 & 4 & 4 \\
\hline Zurich & SWISS(S) & good & good & good & good & 6 & 6 & 6 & 6 \\
\hline Bratislava & $\begin{array}{l}\text { Slovak } \\
\text { Airlines }\end{array}$ & absent & N/A & N/A & $\mathrm{N} / \mathrm{A}$ & -- & $\mathrm{N} / \mathrm{A}$ & $\mathrm{N} / \mathrm{A}$ & $\mathrm{N} / \mathrm{A}$ \\
\hline Budapest & Malév(O) & poor & good & -- & -- & 4 & 4 & $\mathrm{~N} / \mathrm{A}$ & N/A \\
\hline Ljubljana & $\begin{array}{l}\text { Adria Airways } \\
\text { (S) }\end{array}$ & absent & absent & absent & poor & -- & -- & -- & 1 \\
\hline Prague & $\begin{array}{l}\text { Czech Airlines } \\
\text { (ST) }\end{array}$ & good & good & good & good & 4 & 4 & 4 & 3 \\
\hline Riga & Air Baltic & absent & good & good & good & -- & 2 & 2 & 3 \\
\hline Tallinn & Estonian Air & absent & absent & poor & poor & -- & -- & 2 & 2 \\
\hline Vilnius & $\begin{array}{l}\text { Lithuanian } \\
\text { Airlines }\end{array}$ & absent & N/A & N/A & N/A & -- & N/A & $\mathrm{N} / \mathrm{A}$ & N/A \\
\hline Warsaw & LOT(S) & good & good & good & good & 5 & 5 & 4 & 5 \\
\hline Bucharest & TAROM (ST) & absent & poor & poor & poor & -- & 2 & 2 & 2 \\
\hline Sofia & Bulgaria Air & absent & absent & absent & absent & -- & -- & -- & -- \\
\hline Zagreb & $\begin{array}{l}\text { Croatia } \\
\text { Airlines(S) }\end{array}$ & absent & absent & poor & poor & -- & -- & 4 & 4 \\
\hline Chisinau & Air Moldova & absent & absent & absent & absent & -- & -- & -- & -- \\
\hline Kiev & UIA & absent & absent & absent & good & -- & -- & -- & 2 \\
\hline Minsk & Belavia & absent & absent & absent & absent & -- & -- & -- & -- \\
\hline
\end{tabular}

Note: $\mathrm{S}=$ Star Alliance, $\mathrm{ST}=$ SkyTeam and $\mathrm{O}=$ Oneworld.

wave system at Frankfurt and a successful temporal interconnection with the secondary hub in Munich. This can be seen in Figure 3.

As to the temporal coordination, the most frequent morning departure/arrival wave at the selected airports is between $6: 30$ and 8:30 followed by the second significant wave between 15:30 and 17:30. This flight coordination is confirmed by the Brey and Walker [12] statement in which they present a preferred travelling time curve that features clear morning and evening peaks, which, however, are influenced by the type of passenger and the purpose of his/her journey. 

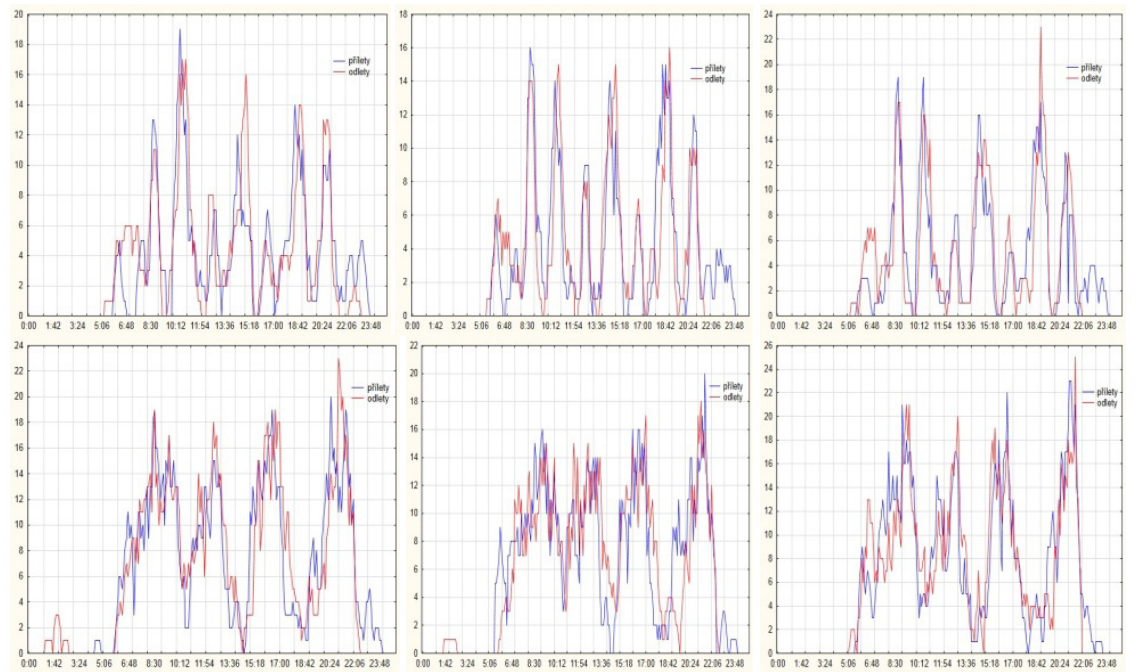

Figure 3: Wave system of Frankfurt and Munich airport in 2009, 2012 and 2013 (in upper row - Frankfurt, in lower row - Munich).

The years 2005 and 2012 have been selected for comparing the number of waves and their quality due to the availability of data on number of passengers at airports in 2012 and due to further possible comparisons in this article. Airports in 2005 can be divided into two groups:

- $\quad$ Group 1 - Prague, Budapest

- $\quad$ Group 2 - Frankfurt, Munich, Zurich, Vienna, Warsaw

Year 2012 presents an obvious transition in the numbers of both groups and airports linked to the onset of new airports adopting the wave system. This made us increase the number of groups to three and reassign the airports; the division in 2012 looks like this:

- Group 1 - Riga, Bucharest, Tallinn, Zagreb

- Group 2 - Prague, Vienna, Warsaw

- Group 3 - Frankfurt, Munich, Zurich

If the number of waves is compared to the population of the city in which the airport is located, three groups with similar characteristics can be formed:

1. Riga, Tallinn

2. Frankfurt, Zagreb

3. Munich, Prague, Warsaw, Vienna

Bucharest and Zurich are among 'atypical' airports.

A diagram has been generated for easier comparison reflecting not only the number of waves but also their quality for each airport. The number of waves has been multiplied by the quality figure where poor $=1$, good $=2$ and very $\operatorname{good}=3$ and the result used for comparison, which brought the following results:

1. Riga, Tallinn, Zagreb

2. Prague, Warsaw, Vienna

3. Frankfurt, Zurich 


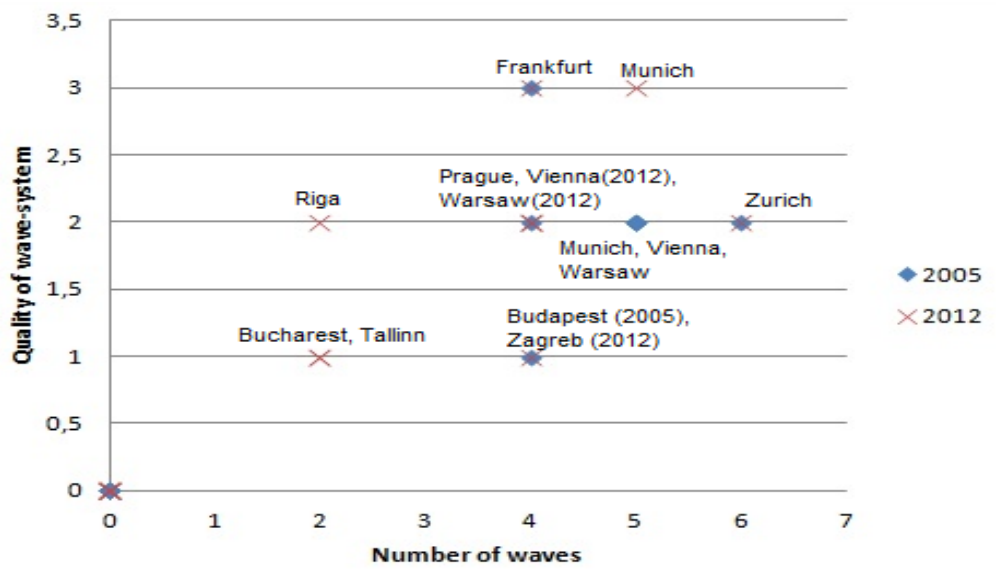

Figure 4: Number and quality of wave-system in 2005 and 2012.

Airports not assigned to any group included Bucharest (again) and newly Munich.

This evaluation is more accurate and better reflects the reality having Frankfurt and Zurich in one group for example - cities that are similar in population and in the number and quality of waves. These are different from Riga, Tallinn and Zagreb with similar populations but significantly lower number and quality of waves than in Frankfurt or Zurich. The population of Bucharest is the highest among the compared cities, but its airport has a very low number and quality of waves. This might be caused by the later joining of the EU and by joining the Skyteam airline alliance as late as in 2010, but also by the insufficient airport capacity due to which construction of a new terminal is planned.

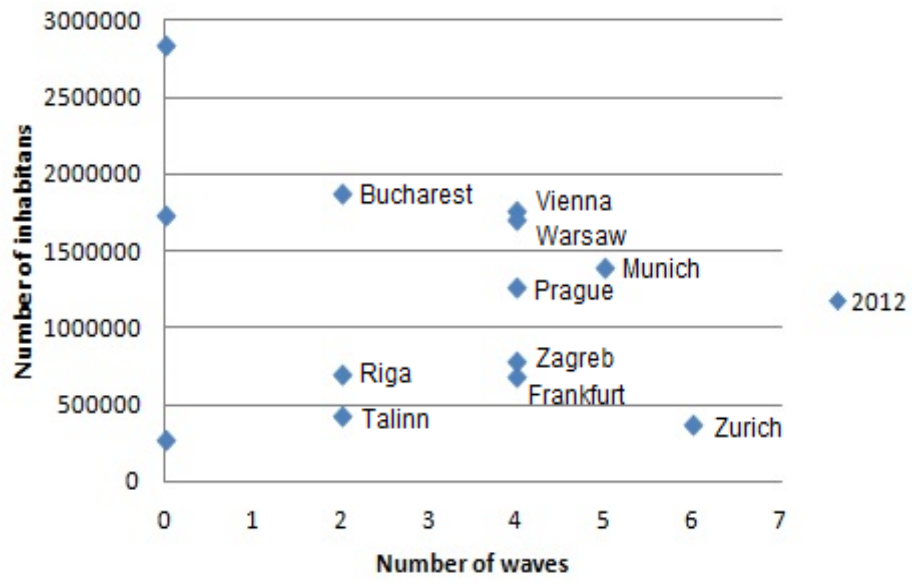

Figure 5: Number of waves in comparison with number of inhabitants in 2012. 


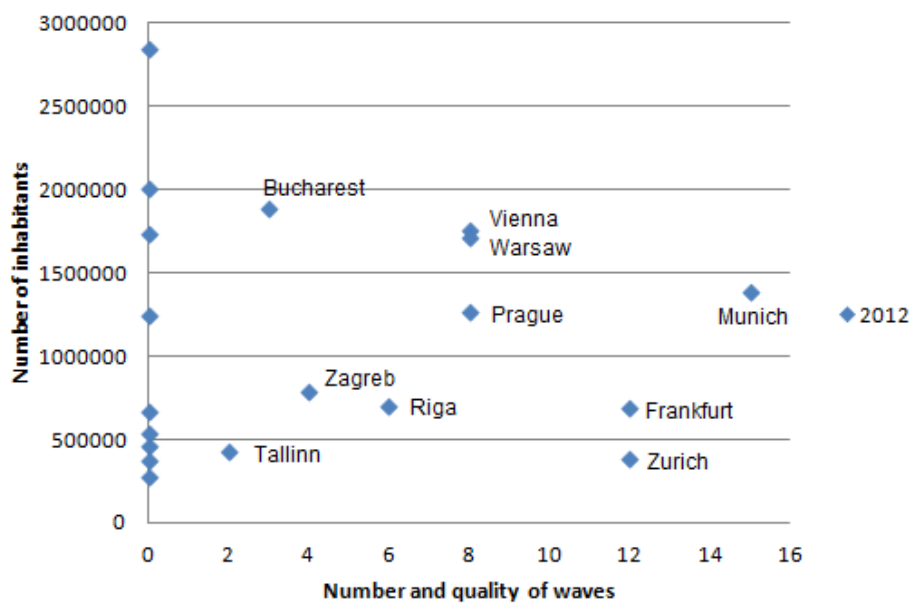

Figure 6: Number of inhabitants with comparison number of wave and the quality in 2012 .

\section{Conclusion}

With respect to the analyses' results, it can be said that the majority of the selected airports in Central and Eastern Europe that are part of the fully liberalized airline space coordinate their flights into temporal waves. The largest and highest-quality systems of waves can be found in countries that have been in a fully liberalized state longest. This phenomenon, however, does not correspond to the population of the city in which the airport is located. Frankfurt and Bucharest can be used as examples, with Frankfurt having one the best wave systems in spite of its population being three times lower than Bucharest, which on the contrary has a number and quality of waves on a very low level. This means that the number and quality of waves depends more on airport location within Central and Eastern Europe than on city size. Thus airports like Frankfurt or Zurich have the highest-quality flight coordination, while Kiev or Minsk do not have any, which - as mentioned earlier - corresponds to the air transport liberalization that has not happened in Minsk.

\section{References}

[1] Burghouwt, G. \& Huys, M., Deregulation and the consequences for airport planning in Europe. Disp, 154, pp. 37-45, 2003.

[2] Burghouwt, G. \& Wit, J. de. Temporal configurations of European airline network. Journal of Air Transport Management, 15(4), pp. 185-198, 2005.

[3] Scholz, A.B. \& Cossel, J van. Assessing the importance of hub airports for cargo carriers and its implications for a sustainable airport management. Research in Transportation Business and Management, 1(1), pp. 62-70, 2011. 
[4] Burghouwt, G. Airline network development in Europe and its implications for airport planning. Aldershot: Ashgate, pp. 287, 2007.

[5] Cento, A. The Airline Industry: Challenges in the 21st Century. Springer, pp. 184. 2009.

[6] Scholz, A. B. Network structures of cargo airlines - An empirical and a modelling approach. KIT Scientific Publishing, pp. 158, 2011.

[7] Danesi, A. Measuring airline hub timetable co-ordination and connectivity-Definition of a new index and application to a sample of European hubs, European Transport, 34, pp. 54-74, 2006.

[8] Malighetti, M., Paleari, S. \& Redondi, R., Connectivity of the European airport network:"self-help hubbing" and business implications. Journal of Air Transport Management, 14(2), pp. 53-65, 2008.

[9] DHV CR \& InterVITAS, Komparativní studie globální dostupnosti města Brna, Brno, pp. 99, 2011.

[10] Dennis, N., Scheduling issues and network strategies for international airline alliances. Journal of Air Transport Management, 6(2), pp. 75-85, 2000.

[11] Murphy, M., Airline strategies in a capacity constraint airport environment. G.A.R.S. Junior Researchers' Workshop, pp. 23, 2009.

[12] Brey, R. \& Walker, J.L., Latent temporal preferences: An application to airline travel. Transportation Research Part A: Policy and Practice, 45(9), pp. 880-895, 2011. 